\title{
Role of social mobilization in tackling the resistance to polio eradication program in underserved communities of Aligarh, India
}

\author{
M. Athar Ansari ${ }^{1}$, Zulfia Khan ${ }^{2}$, Saira Mehnaz ${ }^{3}$, M. Salman Shah ${ }^{4}$, A. Jafar Abedi ${ }^{5}$, Anees Ahmad $^{6}$ \\ ${ }^{1}$ Professor, ${ }^{2}$ Professor and Head, ${ }^{3,4,5}$ Assistant Professors, ${ }^{6}$ Associate Professor, Department of Community Medicine, J. N. Medical \\ College, Aligarh Muslim University, Aligarh, India-2002.
}

\begin{abstract}
Poliomyelitis (polio) is a highly infectious viral disease and mainly affects children under five years of age. The present cross-sectional study was conducted to assess the impact of social mobilization on families resistant to giving polio drops to their children. One round of polio drop administration during September, 2012 was selected randomly from total six rounds of Pulse Polio Immunization campaign carried out in the year 2012 in Aligarh, India. Medical interns of the Aligarh Muslim University were trained as social mobilizers by the UNICEF, Rotary International trainers and divided into Teams ' $A$ ' and ' $B$ '. The teams of social mobilizers visited the households that refused to give polio drops to their children because of certain rumors and misguided beliefs. Medical intern tried to convince the family members that polio drops were safe and it did not hurt any religious and cultural sentiments. The total number of resistant families, identified during the house to house outreach activity of Team 'A' was 309 . A large number of houses $(70.9 \%)$ were converted to $\mathrm{P}$ houses (houses where children had polio vaccination). Ninety houses $(29.1 \%)$ remained resistant even after the activity of Team ' $A$ '. These resistant houses were again visited by Team 'B' members. Out of these 90 houses, polio drops were administered in 70 (78.9\%) houses. However, after maximum efforts of both the teams, only 19 (21.1\%) houses remained extremely resistant. Large numbers of resistant families were converted to $\mathrm{P}$ houses where children were administered oral polio drops. However, some of the families remained resistant even after maximum efforts of the teams. These extremely resistant families might be the potent sources of polio infection in the community and they should be followed up strictly. Strategies and polices should be developed to cover all children of the community by assessing the reasons for families resistance to polio drop, examining the past failures/limitations in program implementation, and implementing the effective social mobilizing techniques.
\end{abstract}

Keywords: Social mobilization, Polio eradication, Resistant houses, High risk areas, India.

\section{Introduction}

Poliomyelitis (polio) is a highly infectious viral disease and mainly affects children under five years of age. One in 200 infections leads to irreversible paralysis. Among those paralyzed, $5 \%$ to $10 \%$ die when their breathing muscles become immobilized. ${ }^{1}$ Globally there were 223 cases, reported in 2012 which included 217 and 6 polio cases in endemic and non-endemic countries respectively. Out of these cases, Nigeria reported maximum number of cases (122) followed by Pakistan (58), Afghanistan (37), Chad (05), and Niger (01). ${ }^{2}$

India became a partner for Global Polio Eradication in 1988. As a part of the Eradication policy, Strategy of National and Sub-National Immunization Days (NIDs and SNIDs) was initiated in 1995, leading to a dramatic drop in number of cases from 30,000 reported cases to 39 cases in 2000. Setbacks to program started in 2002 when new cases steeply rose from 268 in 2001 to 1600 in 2002 (Figure 1). ${ }^{3}$

In India, declining trend of polio cases has been noticed since 1998 setback occurred in 2002 and from 2006 to 2009 large number of cases have been reported. ${ }^{3}$ The last

Practice Points
Poliomyelitis (polio) is a highly infectious viral
disease and mainly affects children under five
years of age.
India's name has been struck off from the list of
endemic countries and India is on the verge of
eradicating polio from the country.
In all high risk areas, effective social mobiliza-
tion programs by medical interns reduced the
number of families resistant to the administra-
tion of oral polio drops.
However, some of the families remained resis-
tant even after the maximum efforts of the
teams, and such families might be potent
sources of polio infection in the community.
Strategies and polices should be developed to
cover all children of the community by assess-
ing the reasons for families' resistance to polio
drop, examining the past failures/limitations in
program implementation, and implementing the
effective social mobilizing techniques.

Correspondence: Dr. M. Athar Ansari, Professor and former Head, Department of Community Medicine, J.N. Medical College, Aligarh Muslim University, Aligarh, India-2002002. E-mail: atharansari777@,rediffmail.com. 


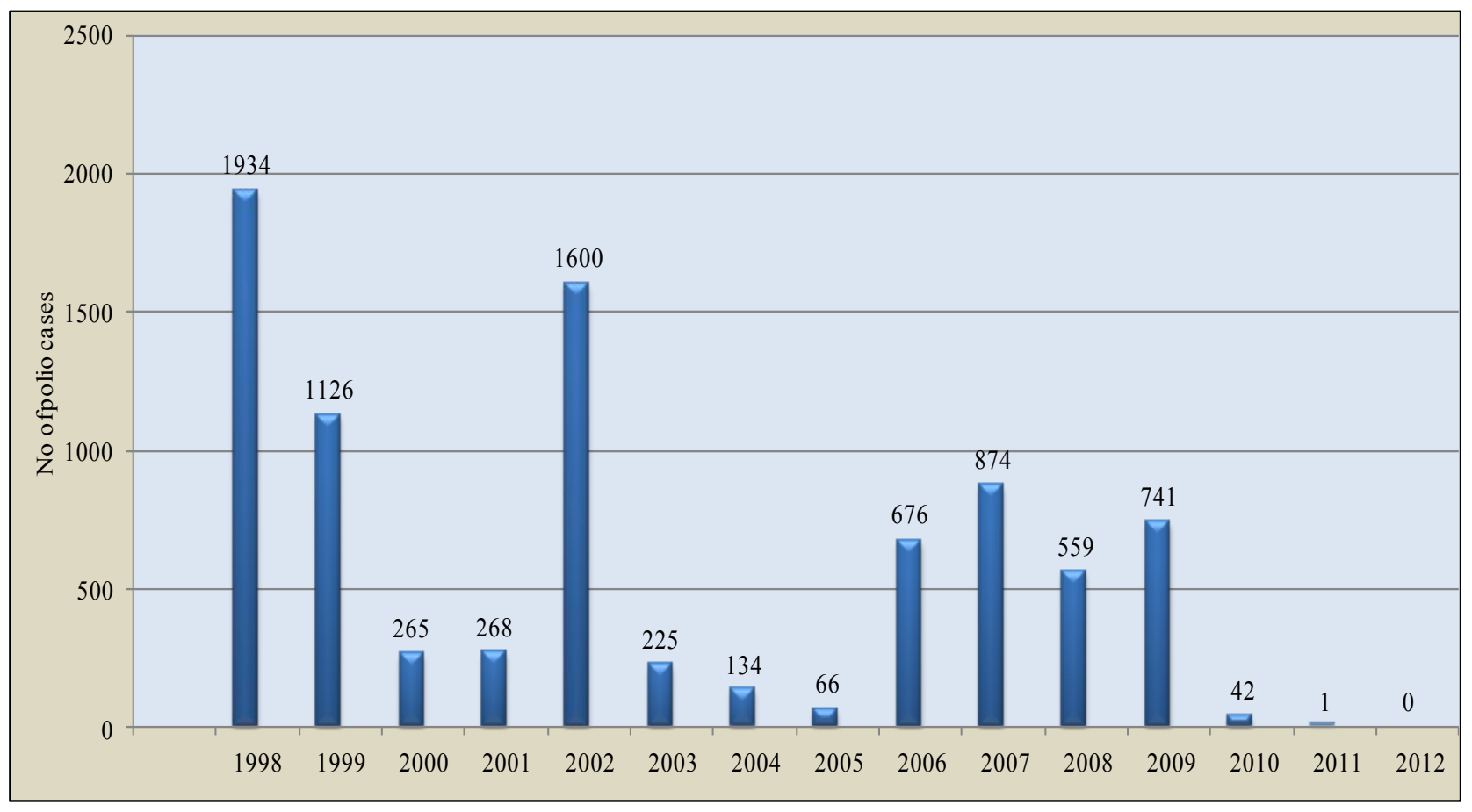

Fig 1: Wild Polio cases in India ${ }^{3}$

case of $P_{1}$ polio virus in India was reported on $13^{\text {th }}$ January 2011 in state of West Bengal and fortunately during last two years no case of any type of polio virus has been reported. ${ }^{4}$ India's name has been struck off from the list of endemic countries. ${ }^{5}$

In 1995, the Government of India, in addition to Routine Immunization Program, introduced the strategy of National Immunization Days (NID) (Pulse Polio Immunization (PPI)) as it was popularly called, in order to step up coverage of polio vaccination, to reduce the immunity gap and to eradicate the disease from all parts of India. ${ }^{6}$ Initially, Pulse Polio Immunization Programme (PPI) enjoyed enormous success and popularity. There was an immense spirit of volunteerism throughout India, which resulted in successfully increasing the Oral Polio Vaccine (OPV) coverage from $85 \%$ in 1995 to $96.1 \%$ in $2000-20011^{7}$

In 1999-2000, the Government of India stepped up the frequency of mass immunization from two national campaigns per year, which normally took place 4 to 6 weeks apart between December and January, to six. It also introduced a series of five Sub-National Immunization Days (SNID) with intensive vaccination of children in eight states where cases of paralytic polio were reported: Assam, Bihar, Gujarat, Madhya Pradesh (M.P.), Orissa, Rajasthan, Uttar Pradesh (U.P.) and West Bengal (W.B.) and the activity was renamed as Intensified Pulse Polio Immunization (IPPI). ${ }^{8}$ This was an effort to reach the remaining $3.9 \%$ children. These $3.9 \%$ or 5.3 million children were those eligible children, between 0-5 years of age, who either did not turn up at the booth or dropped out of the vaccination exercise. ${ }^{8}$ Without reaching these children it was not possible to eradicate the poliovirus from the country.
However, the most backward and underserved communities with little or no access to mass media were probably not reached by these activities. It was also noted that communication between health specialist, national planners and community was poor. The rationale behind administering OPV drops to 0-5 year children through repeated doses over the years was poorly appreciated by the people. ${ }^{9}$ At the same time, in an effort to reach targets, use of force by the health workers in underserved areas added to the resentment against a 'government sponsored programme'. Doubts were raised about government motives in repeated rounds. Doubts left unanswered led to rumors such as polio drops cause infertility, are useless and paralysis may occur in spite of its administration or it causes polio. ${ }^{8}$ People started shutting doors and hiding their children. They told lies and refused to have their children vaccinated, especially males. ${ }^{10}$ At this stage, resistance and rumors against OPV were widespread in the community.

It became clear that the program could not succeed without participation of the community. Efforts were undertaken to break the barrier of resistance by social mobilization.

An analysis of children affected in 2002, Aligarh revealed that these children were below 2 years of age, predominantly Muslim boys. ${ }^{11}$ The majority of cases (80\%) were reported from Western Uttar Pradesh (UP), accounting for $60 \%$ of global cases. ${ }^{12}$ The cases were mostly confined to densely populated urban areas with poor civic amenities. Western Uttar Pradesh was the 'world Epi-centre' for polio in 2003. ${ }^{11}$ World Health Organization (WHO) and Government of India's surveillance data showed that children in 'high risk' 
urban slums of Western UP were being consistently missed during NID or SNID and Routine Immunization sessions and they were primarily Muslims and It was estimated that $3.9 \%$ or $5.3 . \mathrm{m}$ eligible children were missed during the rounds. ${ }^{12,13}$

In 2003 the highest number of cases in India were reported from Aligarh (17 cases, out of which 16 were Muslim) mostly from densely populated areas, which were underserved in terms of healthcare and civic amenities. ${ }^{14}$ In this context the role of minority institutions like AMU and Jamia Hamdard became very important and crucial. Aligarh has the advantage of having the Aligarh Muslim University (AMU). AMU has a special psychological significance for Muslims in India, being a premier educational institution trusted by the Muslims everywhere.

The University was approached by the UNICEF to work towards addressing the resistance in the underserved areas in partnership with UNICEF, Rotary International and District Administration. ${ }^{12}$

As a part of its 'social responsibility', the AMU Polio Eradication Project was taken up by the University under the guidance and chairmanship of its ViceChancellor and in collaboration with the Polio Partners (namely UNICEF, Rotary International, and District Administration). AMU's polio advocacy program headed by the vice chancellor of the university was well accepted by the population in district of Western UP. ${ }^{10}$ AMU is running a project with the support of UNICEF under polio eradication program where health services were provided which also made the community more receptive to the messages regarding polio given by the university. ${ }^{12,13}$

With the introduction of House-to-House (h-to-h) approach from 2000-2001, recommended by the India Expert Advisory Group (IEAG), a shift in the type of vaccinator from volunteers to professionals (auxiliary nurse midwife, health worker and school teachers) took place, as the house-to-house activity lasted for at least 5 days. $^{12,13}$ The average number of people manning each booth plunged from an average of 10 to 14 since 19951996 to 2.9 by $1999-2000{ }^{8}$

Information, Education and Communication (IEC) activities were stepped up by multiple channels of communication, focused on reminding parents of the importance of vaccinating all children below 5 years of age, right from infancy, with TV spots, appeals by politicians and film stars. ${ }^{7,15}$

Keeping in view the fears, suspicion, and resistance to polio drops in urban Aligarh, the underserved strategy was designed by the AMU Task Force, specially set up for this purpose. To reach these resistant pockets in Muslim community and to reduce the resistance, especially in more resistant Western UP including Aligarh, the underserved strategy was introduced and involved religious leaders, health personnel, opinion makers and other influential persons. They are instrumental in removing the misconception regarding polio drops, thereby reducing the resistance in the Muslim community. During the Friday prayer sermon, given by the high priest in the mosques, these rumors were clarified and rectified. ${ }^{13}$

Keeping in mind above facts, this study was undertaken to assess the impact of this social mobilization effort on resistance to the program.

\section{Materials and methods}

This cross-sectional study was conducted in eight high risk urban areas of Aligarh, India where maximum number of resistant families were identified during polio rounds organized by the Government of India. Aligarh is a small district in the state of Uttar Pradesh, situated about $133 \mathrm{Km}$ in south east of Delhi with an area of $5019 \mathrm{Sq} \mathrm{Km}$ and having a population of $3,673,849$. The population of Aligarh city is 872,575 having an estimated 95,983 children in the age group of 0 to 5 years. Of these, $40 \%(38,393$ children $)$ are living in eight high risk areas. ${ }^{16}$ To find out conversion rate by social mobilizers, out of 11 polio rounds conducted in Aligarh, one round of polio immunization campaign (September, 2012) was selected randomly for this study.

Medical interns of the Aligarh University were trained as social mobilizers by the UNICEF, Rotary International trainers for carrying out Team A and Team B Activities. In every team, there was at least one female medical intern to play a vital role. Her presence made the accessibility to the houses easier because most of the male family members were laborers or working in small -scale industries and stayed away from home at the time of visit. Only female members of family were available. The Interns were trained keeping in mind the demographic, socio-economic, cultural and religious factors of the communities. People were living in hard to reach areas, urban slums which were underserved. Training was also given to interns in such a way that they were capable of dealing with the local issues which are not directly related but they had indirect effect on social mobilization program. Sometimes the communities were resistant to polio drops not because of fear of sterility or other side-effects, but for other proxy grievance like basic amenities. They complained of lack or limited availability of healthcare services, supply of drinking water, electricity, power supply, sewage system and waste disposal in the areas. Their demands were directed to the concerned authorities and this helped conversion and strengthened integrated approach of the program involving different polio partners. Other members of the team were Community Mobilization Coordinators (CMC) of UNICEF and some local influential persons. Vaccinators were not the part of the team but they moved with the teams and vaccinated the children in resistant families.

Sunday was the booth day on every polio round where families were supposed to bring their children to booth for vaccination. Most of the time attendance at booth 
was low due to the anticipation that the vaccinators would come on Monday at their door step to vaccinate their children. On Monday vaccinators identified the resistant families refusing vaccination with polio drops. In the daily evening meeting at the district hospital, list of the resistant families were made and handed over to $\mathrm{CMC}$ of the concerned area for next day activity.

Team 'A' activity started on Tuesday and continued for four days. Team A was accompanied by the CMC who took the team of interns to resistant houses. Trained members of the Team A first greeted the families, took note of their grievances and asked about any apprehension regarding polio drops. They tried to counsel the families and answered their doubts. They imparted correct health education in a friendly atmosphere to these resistant families and tried to convince them that polio drops did not have any side effect and it did not cause sterility. After convincing them, polio drops were given to their children. Sometimes the family pretended that child was sick. The interns, then examined the children and if found sick, gave them medicine which they carried with them. The seriously ill children were referred to health centers. These sick children were vaccinated on subsequent days. During house to house Team A activity, most of the resistant or 'XR' houses were converted to ' $\mathrm{P}$ ' houses where polio drops were administered to children. However, during this activity, few resistant families were identified who refused to give polio drops to their children even after exhaustive and skillful social mobilization activity carried out by Team A members.

For these more resistant families Team B activity was carried out 2 to 3 days after the completion of Team A activity. Numbers of Team B were reduced due to less number of resistant houses. Composition of Team B was based on feedback received from the $\mathrm{CMC}$ and medical officer regarding performance of the Team A and individual member who had maximum number of conversion in their working area. Team B members were again briefed about strategy to reach these highly resistant families by the UNICEF personnel. All efforts were made to convince these families but in some of the families, medical interns and other social mobilizers could not succeed. These were extremely resistant families which constituted the vulnerable group posing threat to the children in the community.

Appropriate ethical clearance for the study was obtained from the Institutional Ethical Committee of J.N. Medical College, Aligarh Muslim University, Aligarh (India). Data were collected, collated and analyzed using SPSS 12.

\section{Results}

Table 1 shows the number of houses visited which were resistant and number of houses where children were given OPV during Team A activity. Total number of resistant houses, visited by Team A was 309 which included sick children (XS), locked houses (XH) and purely resistant houses (XR). Practically all three types of houses were considered as resistant as most of the families pretend that child was sick or they locked their houses to prevent the administration of polio drops to their children. Out of 191 houses of sick children, marked as having sick children 26 resistant houses without any apparent reason of denying the polio drops and 2 locked houses were visited by the team members. Total resistant houses with children where polio drops were administered (that is, converted to acceptance) were $219(70.9 \%)$. Maximum number of resistant houses was identified in Naurangabad area but large number of houses was converted to $\mathrm{P}$ houses where polio drops were given to the children $(73.1 \%)$. In Indira Nagar area only 6 houses were found as resistant and all of them were converted to $\mathrm{P}$ houses. However, in K. K. Jain area, large number of houses remained resistant and they did not allow the volunteers to give OPV to their children (46.2\%). After 5 days of Team A activity, 90 houses $(29.1 \%)$ could not be converted to $\mathrm{P}$ houses and these were most resistant houses.

Table 2 presents the number of most resistant houses visited and number of houses where children were given OPV during Team B activity. All the 90 most resistant houses were visited by Team B volunteers. After prolonged counseling and motivation, family members of 71 houses $(78.9 \%)$ allowed administering polio drops

Table 1: Administration of polio drops in resistant houses (Team A activity)

\begin{tabular}{|l|c|c|c|c|c|c|c|c|}
\hline \multirow{2}{*}{ Areas } & $\begin{array}{c}\text { Resistant } \\
\text { houses } \\
\text { visited }\end{array}$ & $\begin{array}{c}\text { XS to P } \\
\text { conversion }\end{array}$ & $\begin{array}{c}\text { XR to P } \\
\text { conversion }\end{array}$ & \multicolumn{2}{|c|}{$\begin{array}{c}\text { XH to P } \\
\text { conversion }\end{array}$} & \multicolumn{2}{|c|}{$\begin{array}{c}\text { Total X houses } \\
\text { converted }\end{array}$} & $\begin{array}{c}\text { Resistant houses } \\
\text { (remaining) }\end{array}$ \\
\cline { 3 - 9 } & $\mathbf{N o}$ & $\mathbf{N o}$ & $\mathbf{N o}$ & No & $\mathbf{\%}$ & No & \% \\
\hline Shahjamal & 45 & 30 & 03 & 00 & 33 & 73.3 & 12 & 26.7 \\
\hline Indra Nagar & 06 & 06 & 00 & 00 & 06 & 100.0 & 00 & 0.0 \\
\hline Jeevangarh & 28 & 18 & 02 & 00 & 20 & 71.4 & 08 & 28.6 \\
\hline Upper Fort & 33 & 19 & 06 & 00 & 25 & 75.8 & 08 & 24.2 \\
\hline K.K.Jain & 39 & 14 & 07 & 00 & 21 & 53.8 & 18 & 46.2 \\
\hline Naurangabad & 104 & 69 & 06 & 01 & 76 & 73.1 & 28 & 26.9 \\
\hline M.A.Nagar & 28 & 17 & 02 & 01 & 20 & 71.4 & 08 & 26.6 \\
\hline Banna Devi & 26 & 18 & 00 & 00 & 18 & 69.2 & 8 & 30.8 \\
\hline Total & $\mathbf{3 0 9}$ & $\mathbf{1 9 1}$ & $\mathbf{2 6}$ & $\mathbf{0 2}$ & $\mathbf{2 1 9}$ & $\mathbf{7 0 . 9}$ & $\mathbf{9 0}$ & $\mathbf{2 9 . 1}$ \\
\hline
\end{tabular}

Keys: XS - Child was sickness, XR - Resistance to polio drops (Refusal), XH - House was locked, P - Child was given polio drops. 
Table 2: Administration of polio drops in more resistant houses (Team B activity)

\begin{tabular}{|l|c|c|c|c|c|}
\hline \multicolumn{1}{|c|}{ Area } & $\begin{array}{c}\text { Resistant houses } \\
\text { visited }\end{array}$ & \multicolumn{2}{c|}{ XR to P conversion } & \multicolumn{2}{c|}{$\begin{array}{c}\text { Resistant houses } \\
\text { (remaining) }\end{array}$} \\
\cline { 3 - 6 } & & No & \% & No & \% \\
\hline Shahjamal & 12 & 09 & 75.0 & 03 & 25.0 \\
\hline Indra Nagar & 00 & 00 & 0.0 & 00 & 0.0 \\
\hline Jeevangarh & 08 & 05 & 62.5 & 03 & 37.5 \\
\hline Upper Fort & 08 & 06 & 75.0 & 02 & 25.0 \\
\hline K.K. Jain & 18 & 12 & 66.7 & 06 & 33.3 \\
\hline Naurangabad & 28 & 26 & 92.9 & 02 & 7.1 \\
\hline M.A. Nagar & 08 & 05 & 62.5 & 03 & 37.5 \\
\hline Banna Devi & 08 & 08 & 100.0 & 00 & 0.0 \\
\hline Total & $\mathbf{9 0}$ & $\mathbf{7 1}$ & $\mathbf{7 8 . 9}$ & $\mathbf{1 9}$ & $\mathbf{2 1 . 1}$ \\
\hline
\end{tabular}

to their children. Maximum number of resistant houses (XR) was converted to P houses in Banna Devi (100\%) and Naurangabad $(92.9 \%)$ areas followed by Upper Fort $(75 \%)$ and Shahjamal $(75 \%)$ areas. However, Team B failed to give polio drops in $19(21.1 \%)$ houses and these were seen as extremely resistant houses. Maximum resistant was seen in K. K. Jain area where 6 children $(33.3 \%)$ could not be administered polio vaccine.

Table 3 summarizes the result of Team A and Team B activities in 8 high-risk areas. Out of 309 resistant houses, identified during house-to-house activity, 290 (93.9\%) houses were converted to $\mathrm{P}$ houses by the workers of Team A and Team B. Conversion rate was high in all high-risk areas except K. K. Jain area where $15.4 \%$ of the houses remained resistant.

\section{Discussion}

The main achievements of the present study is that in all high risk areas maximum numbers of resistant families were converted to $\mathrm{P}$ houses where large numbers of children were given OPV. These families were persuaded and convinced by the teams of interns, social workers and influential persons that polio drops did not have any side- effects. Local influential persons first gave OPV to their children in front of large number of people, thereby removing the fear regarding the OPV in the community.
The people in these areas, especially Shahjamal area, asked for other basic amenities like sanitation, drinking water, health services and electricity. Team members discussed their problems with the district authorities and requested to instruct the person concerned to take appropriate action at the earliest. This helped a lot in reducing the resistance in the families. But this program cannot be linked with their other problems. Resistance was high in K. K. Jain area which was attributed to the fact that a child died after administration of polio drops (due to some other illness) and this news was published in local dailies. Later on, it was found that child died due to other reason not related to polio drops. These extremely resistant families might be the potent source of infection and they should be followed up strictly. All effort should be made to give polio drops in these families.

When the people were told that team members were doctors from medical college, their response was good as compared to response given to other staff members of the district hospital. They were more receptive to the advices given by medical interns. For better compliance health camps were organized by the Department of Community Medicine with the help of UNICEF prior to polio rounds. This also ultimately helped improving the conversion rate. ${ }^{10}$ Similar observations were noticed in a study conducted in Aligarh where a respondent during an interview said that 'Yes, we will go, show our children to the doctor at the Medical College get routine

Table 3: Administration of polio drops (after Team A and B activity)

\begin{tabular}{|l|c|c|c|c|c|}
\hline \multicolumn{1}{|c|}{ Area } & $\begin{array}{c}\text { Total resistant houses } \\
\text { visited }\end{array}$ & \multicolumn{2}{c|}{ Total X houses converted } & \multicolumn{2}{c|}{$\begin{array}{c}\text { Total resistant houses } \\
\text { (remaining) }\end{array}$} \\
\cline { 2 - 6 } & & No & \% & No & 6.7 \\
\hline Shahjamal & 45 & 42 & 93.3 & 03 & 0.0 \\
\hline Indra Nagar & 06 & 06 & 100.0 & 00 & 10.7 \\
\hline Jeevangarh & 28 & 25 & 89.3 & 03 & 6.1 \\
\hline Upper Fort & 33 & 31 & 93.9 & 02 & 15.4 \\
\hline K.K. Jain & 39 & 33 & 84.6 & 06 & 1.9 \\
\hline Naurangabad & 104 & 102 & 98.1 & 02 & 10.7 \\
\hline M.A. Nagar & 28 & 25 & 89.3 & 03 & 0.0 \\
\hline Banna Devi & 26 & 26 & 100.0 & 00 & $\mathbf{6 . 1}$ \\
\hline Total & $\mathbf{3 0 9}$ & $\mathbf{2 9 0}$ & $\mathbf{9 3 . 9}$ & $\mathbf{1 9}$ & \\
\hline
\end{tabular}


care and vaccinate and come back, ${ }^{10}$

Apart from social mobilization, correct health education was also given to the family members especially importance of routine immunization in children. They were asked to come to Medical College Out Patients Department or nearby health clinics with their under five children for immunization against six killer diseases. Medical college has two UNICEF sponsored health clinics in the city area and people were asked to visit these clinics and avail health services provided to them. This also helped reduce the resistant. Similar observations were also made in a report published by the UNICEF. ${ }^{12}$

In a study conducted in Aligarh, India, unclear information and lack of communication was identified as the main reason for resistance to polio drops. ${ }^{10}$ The other finding observed was that families in cities like Aligarh was not provided adequate information regarding polio eradication program and vaccinating every child every month. It was apparent that this might have contributed to fatigue, if not suspicion of the program. ${ }^{10}$ Since this study was conducted in 2009 and in different setting, reasons for resistance might be different as observed in our study.

Several evaluations and studies show how these activities have contributed to the Global Polio Eradication Initiative's efforts. Communities where social mobilization activities are conducted are consistently less likely to refuse OPV, more likely to attend booths and more likely to report positive attitudes towards OPV and higher perception of polio risk. ${ }^{13,17}$ In four high-risk districts of Uttar Pradesh where social mobilization activities were conducted, the number of wild poliovirus cases dropped from 116 to 49 and there was a significant increase in booth coverage between $50 \%$ and $57 \%$, compared with $19-35 \%$ at district level. ${ }^{8}$ A one-year longitudinal study in 13 districts of Uttar Pradesh demonstrated that booth coverage was 8 to $12 \%$ higher in areas with a community mobilization coordinator than in areas without one. ${ }^{13}$ Similar observations were found in a study conducted in Surat, India. ${ }^{17}$

Other studies found a statistically significant difference $(P<0.05)$ in families' positive attitudes and behaviors towards OPV. ${ }^{18,19}$ An evaluation of the role of community mobilization coordinators in Uttar Pradesh pointed to a $20 \%$ increase among families who reported that interaction with community mobilization coordinators influenced their intention to vaccinate their children. ${ }^{20}$ Strategies and polices should be developed to cover all children of the community by assessing the reasons for families resistance to polio drop, examining the past failures/limitations in program implementation, and evaluating the lessons learnt from previous eradication plans.

The study has a number of limitations. This crosssectional study involved only polio drops resistant families of Aligarh and had a small sample size; therefore, caution needs to be taken to generalize the findings. This study was also conducted only in areas with available social mobilization network of the UNICEF due certain constraints. It would have given more valid results if comparison was done in two different settings: one with available social mobilization network and one without it. Moreover, as this is a crosssectional study, associations have been established among variables but not the casual inferences.

\section{Conclusion}

Large numbers of resistant families were converted to $\mathrm{P}$ houses where children were administered oral polio drops. High rate of conversion was achieved by the effective social mobilization activities. However some of the families remained resistant even after maximum efforts of the teams. These extremely resistant families might be the potent source of infection and may transmit the infection in the community. Hence, they should be followed up strictly. All efforts should be made to impart correct health education regarding importance of polio drops and routine immunization. There is a need to carry out polio eradication campaign more vigorously through information, education and communication (IEC) activities. District authorities should focus on issues related to basic amenities of the community. Communication strategies such as mobilizing social networks and community leaders, creating political will, increasing knowledge and changing attitudes, overcoming gender barriers and, above all, reaching out to the poorest and the most marginalized population of the community. It is important to cover unserved and underserved population as they would continue to play a central role in the final push to eradicate polio. $^{21}$

\section{Acknowledgement}

The research team acknowledges the help provided by Community Mobilization Coordinators (CMC) of UNICEF in the field. We are also thankful to our medical interns for carrying out social mobilization and subsequently reducing the number of resistant houses.

\section{Competing Interest}

The authors have declared that no competing interests exist.

\section{References}

1. World Health Organization. Poliomyelitis. http:// www.who.int/mediacentre/factsheets/fs114/en/ index.html (accessed November 2013)

2. The Global Polio Eradication Initiative. Polio this week. http://www.polioeradication.org/ Dataandmonitoring/Poliothisweek.aspx (accessed November 2013)

3. Global Polio Cases - Rotary Polio Plus India. http://www.rotarypolioplusindia.org/Download/ polioincidence-2011-2012 (accessed Dec 2013) 
1. UNICEF. India records one year without polio cases (Press release) http://www.unicef.org/ media/media_61279.html (accessed Dec 2013)

2. UNICEF. India. Polio eradication. http:// www.unicef.org/india/health $3729 . \mathrm{htm}$ (accessed Dec 2013)

3. John TJ, Vashishtha VM. Eradicating poliomyelitis: India's journey from hyperendemic to polio -free status. Indian J Med Res 2013;137(5):88194.

4. Cheng W. When every child counts: engaging the underserved communities for polio eradication in Uttar Pradesh, India [working paper]. New Delhi: United Nations Children's Fund Regional Office for South Asia; 2004.

5. UNICEF. A Critical Leap to Polio Eradication in India. Kathmandu: United Nations Children's Fund Regional Office for South Asia, 2003.

6. AIIMS-India CLEN. Barriers in Polio Eradication. An AIIMS-India CLEN Study, 2000-2001. All India Institute of Medical Sciences, New Delhi, India.

7. Hussain RS, McGarvey ST, Shahab T, Fruzzetti LM. Fatigue and fear with shifting polio eradication strategies in India: a study of social resistance to vaccination. PLOS One 2012;7(9):1 -9 .

8. AFP Alert. National Polio Surveillance Project. New Delhi: World Health Organization, 2002.

9. UNICEF. Where Every Child Counts. Working Paper. Kathmandu: United Nations Children's Fund Regional Office for South Asia, 2004.
10. Obregon R, Chitnis K, Morry C, Feek W, Bates J, Galway M, Ogden E. Achieving polio eradication: a review of health communication evidence and lessons learned in India and Pakistan. B World Health Organ 2009;87(8): 624 -30 .

11. Ansari MA, Khan Z, Khan IM. Reducing resistance against polio drops. $J$ R Soc Promo Health 2007;127(6): 275-8.

12. Pulse Polio programme starts on Sunday. http:// articles.timesofindia.indiatimes.com/keyword/ pulse-polio/featured/5 (accessed November 2013)

13. Census of India, 2011. $\underline{\text { http:// }}$ www.census2011.co.in (accessed November 2013)

14. Bipin V, Goti P, Rupani M, Mandaviya V, Chudasma R. Evaluation of intensive pulse polio immunization in district dang during 2008. Natl J Community Med 2010;1(2):132-4.

15. Hornik RC. Public health communication: Evidence for behavior change. Mahwah, NJ: Lawrence Erlbaum Associates, 2002.

16. Salmon C, Murray-Johnson L. Communication campaign effectiveness: critical distinctions. In: Rice R, Atkins C, eds. Public communication campaigns. $3^{\text {rd }}$ ed. Thousand Oaks, CA: Sage, 2003.

17. Cheng W. Polio eradication India: reaching the last child. Kathmandu: United Nations Children's Fund Regional Office for South Asia, 2004.

18. Paul Y. What needs to be done for polio eradication in India? Vaccine 2007;25:6431-6. 